\title{
THE USE OF AUTO-TRAINING FOR THE CORRECTION OF FATIGUE IN ADULTS
}

\author{
Lola Nazirova ${ }^{1}$
}

\section{Abstract}

The article describes corrective work with leaders who have expressed a negative attitude towards work. The effectiveness of autogenic psychosomatic training is considered. Improvements were noted due to the elimination of fatigue, which contributed to an improvement in the attitude to the subjects' professional activities.

Key words: emotional stability, empathy, self-regulation leader.

doi: http://doi.org/10.15350/L_2/5/49

Коррекционная работа строилась на основе системного подхода, позволяющего раскрыть многоуровневость и иерархию детерминат, определяющих психические состояния и работоспособность участника занятия. Системность и комплексность в нашем исследовании обеспечивается моделированием условий, набором методов оценки состояний и работоспособности лидера. Исследования проводились на 18 ти испытуемых в возрасте 35-42 лет, не имеющих отклонений в состоянии здоровья, лидеры, выразившие негативное отношение к работе. Исследование проводилось в комнате психологической разгрузки.

Формирование строгих мотивационных установок обеспечивалось специальным подбором испытуемых, для которых получение в методиках и деятельности наивысших результатов имело профессионально - престижный характер, а также применение способов материального стимулирования, связанных со степенью выполнения программы эксперимента, качество которых контролировалось.

Традиционными методами исследовались психофизические и психофизиологические характеристики. Для оценки функционального состояния были использованы методы самооценки. В процессе исследования для оценки функционального состояния участника занятия периодически регистрировались частота сердечных сокращений, частота дыхания.

Коррекционная группа состояла из девяти человек. Нами изучалась эффективность аутогенных психосоматических тренировок (АТ). В исследовании применялась методика Л.П.Гримака с длительностью звучания до 17 минут. Первая половина предусматривала предварительную релаксацию с последующей разгрузкой от напряжения, а вторая с нормализацией самочувствия, повышения работоспособности [21]. Методика разработана для стимуляции работоспособности. В нашем исследовании была предпринята попытка изучения влияния АТ как способа волевой осознанной саморегуляции на работоспособность лидеров, кандидатов на руководящую должность в режиме речевой связи в условиях утомления.

Одной группе (экспериментальная) предлагалось прослушать через наушники магнитофонную запись АТ в течении 18 минут. Другой группе (контрольная) испытуемых в этот момент предоставлялось время для отдыха или сна по жела-

${ }^{1}$ Lola Nazirova, Candidate of Psychological Sciences, Senior Lecturer, Tashkent State Pedagogical University, Uzbekistan. 
нию. Изменение показателей влияния АТ на общее состояние испытуемого проводилось с использованием методики «САН» до начала и после 6 сеансов АТ. До начала эксперимента часть испытуемых заранее прошла курс обучения АТ, другая рассматривалась как контрольная группа. Отработка методов АТ начиналась с освоения простых упражнений релаксации и сосредоточения - самых важных во всем комплексе занятий. Занятия проходили в положении сидя (поза кучера). C каждым испытуемым до начала эксперимента было проведено 9 занятий. Тексты занятий записаны на диск с наложением на функциональную музыку. Длина текста рассчитана на 18 - 20 минут. Освоение курса специального АТ, разработанного на коррекцию работоспособности, проводилось на втором этапе обучения по индивидуальной программе. Прослушивание текста проводилось каждые 7-8 часов, через наушники в положении сидя. Первая половина текста была рассчитана на глубокую релаксацию и освобождение от утомления, вторая - нормализацию самочувствия, повышению психофизиологического тонуса, активизацию педагогических функций.

Психофизиологический анализ функциональных перестроек под влиянием АТ изучался во многих работах.

Системный подход в исследовании регулирующего влияния АТ как метод саморегуляции предполагает необходимость изучения системных перестроек в основном в деятельности и в работе мозга в процессе формирования новых функциональных систем саморегуляции.

Оценка самочувствия, активности и настроения высчитывалось путем подсчета балов по показателям плохое и хорошее самочувствие.

Плохое самочувствие, низкая активность и плохое настроение за 1бал (индекс 3), 2 бала за индекс 2, 3 бала за индекс 1 и так до 7 балов.

Положительные состояния получают высокие балы, негативные состояния низкие балы.

Самочувствие - 10 ответов - максимальный бал 7 минимальный 1 ;

Активность - 10 ответов - максимальный бал 7 минимальный 1 ;

Настроение -10 ответов - максимальный бал 7 минимальный 1.

Исходя из этого 7 балов - 100\%, соответственно средний показатель 3,5 $50 \%, 1.4-20 \%$.

Высокий показатель САН от выше 50\% до100\%,

Средний показатель от $21 \%$ до $50 \%$,

Низкий показатель от 0 до $20 \%$.

Результаты методики САН. Данные обследования занесены в сводную таблицу №1. «Показатели Самочувствия экспериментальной (А) и контрольной (В) группы, до прохождения АТ».

У большинства испытуемых на начало эксперимента выражены низкие балы по показателю самочувствия (учет результатов по АД - артериальное давление, пульс). При беседе было выявлено наличие головной боли у двоих испытуемых, головокружение.

У большинства испытуемых на начало эксперимента выражены средние балы по показателю активности. Начало рабочей недели предполагает большие показатели. Однако наблюдается отсутствие желания эффективно работать. 
Таблица 1

Показатели Самочувствия, активности и настроения экспериментальной

(А) и контрольной (В) группы, до прохождения АТ

\begin{tabular}{|c|c|c|c|c|c|c|c|c|c|}
\hline \multirow{2}{*}{$\begin{array}{c}\text { Группы п = } 9 \text { испыту- } \\
\text { емых }\end{array}$} & \multicolumn{3}{|c|}{ Высокие балы } & \multicolumn{3}{|c|}{ Средние балы } & \multicolumn{3}{|c|}{ Низкие балы } \\
\hline & C. & $\mathrm{A}$ & $\mathrm{H}$ & $\mathrm{C}$ & $\mathrm{A}$ & $\mathrm{H}$ & $\mathrm{C}$ & $\mathrm{A}$ & $\mathrm{H}$ \\
\hline $\begin{array}{c}\text { Экспериментальная } \\
\text { группа }\end{array}$ & 1 & 3 & 4 & 3 & 3 & 5 & 5 & 3 & - \\
\hline Контрольная группа & 2 & 4 & 3 & 3 & 5 & 4 & 4 & - & 2 \\
\hline
\end{tabular}

У большинства испытуемых на начало эксперимента выражено настроение внутри нормы без астении и эйфории.

В целом показатели средних балов группы А равны настроение - 5,6. Показатели группы B - 6,7 балов; активности - 5,8 группа A, группа B- 6,7балов, группа А показатель самочувствия - 5,3, группа В - 5,6 балов.

На втором этапе испытуемые группы А в перерывах занимались АТ, тогда как испытуемые группы В могли просто отдохнуть или поспать.

Мы провели экспресс методику САН по окончанию прохождения коррекционного курса. Полученные показателей самочувствия отражены в таблице 2. «Показатели самочувствия испытуемых экспериментальной и контрольной групп».

Таблица 2

Показатели Самочувствия, активности и настроения экспериментальной (А) и контрольной (В) группы, до прохождения АТ

\begin{tabular}{|c|c|c|c|c|c|c|c|c|c|}
\hline \multirow{2}{*}{ Группы п = } & \multicolumn{3}{|c|}{ Высокие балы } & \multicolumn{3}{c|}{ Средние балы } & \multicolumn{3}{c|}{ Низкие балы } \\
\cline { 2 - 12 } & С. & А & H & С & А & H & С & А & H \\
\hline $\begin{array}{c}\text { Экспериментальная } \\
\text { группа }\end{array}$ & 5 & 5 & 6 & 4 & 4 & 3 & - & - & - \\
\hline Контрольная группа & 2 & 3 & 3 & 4 & 6 & 3 & 3 & - & 3 \\
\hline
\end{tabular}

На графике 2 представлены изменения по показателям САН в экспериментальной группе до и после прохождения АТ. 1,2.3-САН высокие балы; 4,5.6 -САН средние балы; 7,8,9 -САН низкие балы. Наблюдается тенденция улучшения самочувствия. Снижение Артериального давления, улучшение показателей сердечно сосудистой системы. Снизилось головокружение и боль.

Активность испытуемых экспериментальной группы выросла на несколько единиц. Испытуемые отмечают, что наблюдают прилив сил, более спокойное отношение к конфликтам и другим негативным явлениям в профессиональной деятельности. В результате успешного осуществления должностных обязательств многие испытуемые отмечают улучшение настроения и прилив сил от данных эмоций. Речь не идет об эйфории либо самообмане, речь идет о стабилизации внутренних процессов жизнедеятельности мозговой активности. Проведенное исследование позволяет сделать следующие выводы относительно применения аутотренинга практике профилактики утомляемости. Стимулирующее влияние АТ на деятельность испытуемых экспериментальной группы проявилось в изменении следующих характеристик: улучшились показатели самочувствия: пульс, артериальное давление, сердечный ритм, отдышка, сонливость раздражительность, головные боли (сосудистой этиологии) головокружение. Повысилась активность: решение профессиональных задач без раздражения и психоэмоциональных срывов в процессе наличия конфликтных ситуаций. Улучшилось настроение: чувство 
юмора, творческий подход к решению профессиональных задач, инициатива и легкость в общении. Наблюдалось снижение субъективности повышение объективности восприятия реальности.

Выводы:

1.Эксперимент подтвердил стимулирующее влияние АТ на повышение показателей САН испытуемых экспериментальной группы. Для достоверности результатов и повышения их надежности исследование необходимо проводить на репрезентативной выборке.

2.Проведенное исследование доказало возможность регулирование функционального состояния педагогов с помощью АТ, действие которого направлено на активизацию психофизиологических резервов организма. Это приводило к тому, что после сеансов АТ педагоги отмечали снижение чувства усталости, появления интереса к работе, к её конечным результатам.

3.Использование зрительных, слуховых, тактильных и других сигналов-стимулов, позволяет развить навыки саморегуляции за счет тренировки и повышения лабильности регуляторных механизмов, что способствует преодолению чувства утомления персонала в течении рабочей смены.

4.Гендерные особенности различий влияния АТ нами не обнаружены.

5.При работе с лидерами имеющие негативное отношение к работе по причине утомляемости после прохождения коррекционных занятий удалось изменить отношение с негативного на позитивное. В остальных случаях имелось наличие затруднения общения, в этом случае мы рекомендовали прохождение тренинга общения.

6.В каждом случае негативное отношение к работе имеет свою причину. Коррекция должна строится с учетом причин, влияющих на негативность отношения. Причины эти устанавливаются в ходе беседы по результатам диагностики.

Проблема подготовки руководящих кадров напрямую связано с решением проблем реализации Лидеров. Лидер человек активный, целенаправленный осознанно подходящий к решению проблемных задач. Он ответственно относится к делу. У лидера развит интеллект, и он имеет развитый творческий интеллектуальный потенциал. Однако не всегда этот потенциал реализуется. Возможно существует много причин такого положения дел. Наше исследование показало, что одной из таких причин является негативное отношение к профессиональной деятельности. В этом случае невозможно верно подойти к решению задач. Ограниченность в самих установках затрудняет свободу мысли и использованию сочетаний дивергентности мышления с точностью принятия решения. Творческие показатели должны быть подкреплены минимальностью ошибок. Достижения в профессиональной деятельности важны как для лидера так и для акмеологического статуса. Интеллектуальный потенциал у людей зрелого возраста с выраженными лидерскими качествами раскрывается в определенных условиях. Эти условия изучены нами.

XXI век -век перенасыщения информацией, век сложных ответственных решений, век психоэмоционального перенапряжения на фоне роста технологий и инноваций. В таких условиях Лидера преследуют разочарования и неудовлетворенность от нехватки времени и избыток нерешенных задач и проблем. Понятие отсутствия времени связано с понятием отсутствия возможности восстановления и отдыха. Отдыхать значит спать? Или заниматься спортом или хорошо питаться.

В своем исследовании мы предлагаем организационному психологу использовать в качестве альтернативы при работе с руководящими кадрами методику AT. Зачастую, отдыхать это значить, уметь регулировать свои психофизиологические процессы. Еще в 60е годы Российские физиологи доказали, что можно и нужно 
учиться контролировать свои внутренние процессы и состояния. Мы возвращаемся к истокам психологии, которая ставку делала на самого человека при решении проблем его активности. И затем речь шла о факторах. Необходимо учитывать природный потенциал и резерв личности, который помогает ей реализоваться. Какова бы не была природа этих состояний (физиологическая, психологическая, социальная) организационному психологу необходим точный, абсолютно, действующий на всех вышеописанных уровнях, метод изменения состояния человека. Это состояние может варьироваться от дискомфорта до комфорта, от неудовлетворенности до удовлетворения, от апатии к активности, от депрессии до эйфории, от утомления до работоспособности, от напряженности к расслаблению. Список возможностей метода саморегуляции можно продолжать бесконечно. В своем курсовом проекте мы рассмотрели возможности и перспективы так называемого метода, принципа, подхода под названием биологическая обратная связь. Биологическая обратная связь (англ. Biofeedback) - технология, включающая в себя комплекс исследовательских, лечебных и профилактических физиологических процедур, в ходе которых пациенту посредством внешней цепи обратной связи, организованной преимущественно с помощью микропроцессорной или компьютерной техники, предъявляется информация о состоянии и изменении тех или иных собственных физиологических процессов. В нашем случае в качестве обратной связи нами была использована запись АТ. При этом используются зрительные, слуховые, тактильные и другие сигналы-стимулы, что позволяет развить навыки саморегуляции за счет тренировки и повышения лабильности регуляторных механизмов.

Эксперимент подтвердил стимулирующее влияние АТ на повышение показателей САН испытуемых экспериментальной группы. Улучшение состояния за счет снятия утомляемости способствовало улучшению отношения к профессиональной деятельности испытуемых, что позволило повышению реализации интеллектуального потенциала лиц зрелого возраста с выраженными лидерскими качествами. Гипотеза подтвердилась. Для достоверности результатов и повышения их надежности исследование необходимо проводить на репрезентативной выборке.

\section{Библиографический список}

[1] Александер Ф. Психосоматическая медицина. М., 2000.

[2] Кабанов М. М. Психосоциальная реабилитация и социальная психиатрия. СПб, 1998.

[3] Свенцицкий А. Л. Социальная психология управления. СПб, 1986.

[4] Чалдини Р. Психология влияния. СПб, 1999.

[5] Ялом И. Групповая психотерапия. СПб, 2000

\section{References}

[1] Aleksander F. Psihosomaticheskaya medicina. M., 2000.

[2] Kabanov M. M. Psihosocial'naya reabilitaciya i social'naya psihiatriya. SPb, 1998.

[3] Svencickij A. L. Social'naya psihologiya upravleniya. SPb, 1986.

[4] CHaldini R. Psihologiya vliyaniya. SPb, 1999.

[5] YAlom I. Gruppovaya psihoterapiya. SPb, 2000 